\title{
NOTE ON A SAMPLE OF ADULTERATED COFFEE.
}

By T. H. Pearmain and C. G. Moor, M.A.

(Read at the Meeting, June 5, 1895.)

WE have recently obtained a small sample of adulterated coffee, which we are informed is about to be placed on sale in this country. As the results obtained on examining the sample are somewhat interesting, we thought this note would be worth communicating to the society. The sample gave on analysis the following figures :

\begin{tabular}{llllllc} 
& & & & & \multicolumn{2}{c}{ Per cent. } \\
Moisture & $\ldots$ & $\ldots$ & $\ldots$ & $\ldots$ & $\ldots$ & 3.2 \\
Fat & $\ldots$ & $\ldots$ & $\ldots$ & $\ldots$ & $\ldots$ & $12 \cdot 3$ \\
Total ash & $\ldots$ & $\ldots$ & $\ldots$ & $\ldots$ & $\ldots$ & $3 \cdot 4$ \\
Insoluble ash & $\ldots$ & $\ldots$ & $\ldots$ & $\ldots$ & $\ldots$ & $0 \cdot 7$ \\
Soluble ash & $\ldots$ & $\ldots$ & $\ldots$ & $\ldots$ & $\ldots$ & $2 \cdot 7$ \\
Nitrogen & $\ldots$ & $\ldots$ & $\ldots$ &.. & $\ldots$ & $2 \cdot 7$
\end{tabular}

A filtered 10 per cent. decoction had the same specific gravity as genuine ccffee, namely, 1009.5. After some little trouble we found the sample to consist of exhausted coffee, together with ground acorns.

We were unable to isolate any appreciable quantity of caffeine from the sample. The microscopical appearance of the sample is remarkable, and would render its detection easy even if mixed in small proportion with genuine coffee. In addition to the well-known coffee structures are a number of starch-containing cells, arranged not unlike the heads of Indian corn, together with cellular membrane-containing spiral vessels, which we found to be characteristic of ground acorns.

On the Hübl Method of Iodine Absorption. Julius Ephraim. (Zeit. für angewand. Chemie, Heft ix., 1895, pp. 254-259.) - Since the Hübl solution, when titrated with thiosulphate, requires a much larger quantity of the latter after the addition of $\mathrm{KI}$, the conclusion is arrived at that a substance capable of liberating I from KI must be present. This substance is probably a compound of iodine and chlorine formed by the action of the iodine on the $\mathrm{HgCl}_{2}$. On mixing the two portions of the Hübl solution it appears to be formed at once. Thus the author obtained the following results :

25 c.c. Huibl Solution required.

$\mathrm{Na}_{2} \mathrm{~S}_{2} \mathrm{O}_{3}$.

I. Immediately after mixing :

c.c.

$\begin{array}{llllll}\text { (a) Without KI } \quad \ldots & \ldots & \ldots & \ldots & 14 \cdot 30\end{array}$

$\begin{array}{llllll}\text { (b) With KI } \ldots & \ldots & \ldots & \ldots & \ldots & 14 \cdot 30\end{array}$

II. After twenty minutes :

$\begin{array}{llllll}\text { (a) Without KI } & \ldots & \ldots & \ldots & \ldots & 14 \cdot 45\end{array}$

$\begin{array}{llllll}\text { (b) } \text { With KI } \ldots & \ldots & \ldots & \ldots & \ldots & 50 \cdot 25\end{array}$

III. After four hours fifty minutes :

$\begin{array}{llllll}\text { (a) Without KI } & \ldots & \ldots & \ldots & \ldots & 13 \cdot 25\end{array}$

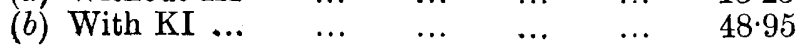

(1 c.c. $\mathrm{Na}_{2} \mathrm{~S}_{2} \mathrm{O}_{3}=0.01223$ gramme I.) 
He next shows that both iodine monochloride and iodine trichloride can be titrated directly with $\mathrm{Na}_{2} \mathrm{~S}_{2} \mathrm{O}_{3}$, and proves that the latter cannot be the compound present in the Hübl solution, since results altogether discordant are obtained when it is tried with commercial oleic acid.

Hübl's requirement, that for two atoms of iodine there must be at least one molecule of $\mathrm{HgCl}_{2}$, may be explained by the following equation, on the assumption that iodine monochloride is the compound formed :

$$
\mathrm{HgCl}_{2}+\mathrm{I}_{2}=\mathrm{HgClI}+\mathrm{ICl} \text {. }
$$

To make a solution corresponding to the strength of the Hübl solution this would give 16.25 grammes of $\mathrm{ICl}$ per litre, and this proportion is used by the author for his solution.

Since iodine monochloride as met with in commerce is seldom quite pure, it is not sufficient merely to ascertain the amount of real $\mathrm{ICl}$ which it contains by titration with the addition of $\mathrm{KI}$, but also without, so that the amount of I which the impurities in the $\mathrm{ICl}$ are capable of liberating in the substance itself may be ascertained.

The method, which is carried out in the same way as the Hübl process, gave the following results :

Oil.

Oleic acid, I. ... $\quad \ldots \quad$...
Iodine Number with Jodine Monochloride.

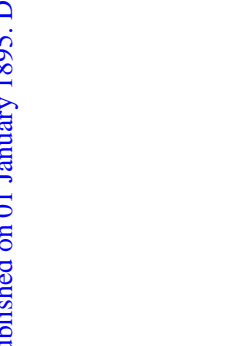

IV.... $\quad \ldots \quad \ldots$
$82 \cdot 7$

$82 \cdot 77$

" $\quad$ II. $\ldots, \quad \ldots \quad \ldots$

,$\quad$ III. ... $\quad \ldots \quad \ldots$

$\begin{array}{ccc}\text { Linseed oil, I. } & \ldots & \text {. } \\ \text { II. } & \ldots & \text {. }\end{array}$

Olive oil, I. $\quad . . \quad$... $\quad$...

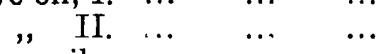

Poppy oil $\quad \ldots \quad \ldots \quad \ldots$

Sesame oil, I. $\quad \ldots . \quad \ldots$

Earthnut oil. II.

Castor oil, I II.

Almond II.

",

il, $\mathrm{I}$.

$\cdots$

...

$\cdots$

$\cdots$

$82 \cdot 5$

$82 \cdot 74$

$179 \cdot 7$

$177 \cdot 7$

83.9

$84 \cdot 00$

$81 \cdot 13$

$137 \cdot 1$

$137 \cdot 1$

$110 \cdot 6$

$109 \cdot 7$

83.33

83.09

$96 \cdot 00$

$96 \cdot 29$
Hiibl Iodine

Number.

$82 \cdot 84$

$179 \cdot 9$

$84 \cdot 3$

$81 \cdot 9$

$137 \cdot 3$

$111 \cdot 1$

From these figures the author concludes that a solution of iodine monochloride in alcohol may be substituted for the Hübl solution. The advantages are that it is more readily prepared, being easily soluble in alcohol, and when made is ready for immediate use. Moreover, it can be made in much more concentrated solution, and, lastly, is cheaper. Its chief disadvantage is that it is not yet made in a state of sufficient purity, and, therefore, each fresh quantity obtained must be titrated, as mentioned above.

If the ICl solution, after acting on the oil, be titrated without previous addition of KI, a new value is obtained, which the author calls the "chlor-iodine number." In titrating, the thiosulphate is added until the liquid, which had become brown with separated iodine, again becomes yellow. The solution is then diluted, starch added, and the titration completed. 
The reaction taking place is :

$$
\mathrm{ICl}+2 \mathrm{Na}_{2} \mathrm{~S}_{2} \mathrm{O}_{3}=\mathrm{NaI}+\mathrm{NaCl}+\mathrm{Na}_{2} \mathrm{~S}_{4} \mathrm{O}_{6}
$$

in which 161.5 parts of $\mathrm{ICl}=316$ of $\mathrm{Na}_{2} \mathrm{~S}_{2} \mathrm{O}_{3}$. The following chlor-iodine numbers were obtained :

\begin{tabular}{lllllll} 
& & & & \multicolumn{1}{c}{ I. } & & \multicolumn{1}{l}{ II. } \\
Earthnut oil & $\ldots$ & $\ldots$ & $\ldots$ & $56 \cdot 6$ & $\ldots$ & $55 \cdot 91$ \\
Linseed oil & $\ldots$ & $\ldots$ & $\ldots$ & $77 \cdot 03$ & $\ldots$ & $76 \cdot 7$ \\
Sesame oil & $\ldots$ & $\ldots$ & $\ldots$ & $65 \cdot 3$ & $\ldots$ & $65 \cdot 0$ \\
Rape-seed oil & $\ldots$ & $\ldots$ & $\ldots$ & $50 \cdot 4$ & $\ldots$ & $50 \cdot 06$ \\
Poppy oil... & $\ldots$ & $\ldots$ & $\ldots$ & $43 \cdot 4$ & $\ldots$ & $43 \cdot 4$ \\
Castor oil ... & $\ldots$ & $\ldots$ & $\ldots$ & $44 \cdot 24$ & $\ldots$ & $43 \cdot 88$
\end{tabular}

A few experiments tried with iodine bromide also gave concordant results :

\begin{tabular}{lccccccc} 
& & \multicolumn{3}{c}{ II. } & \multicolumn{2}{c}{ III. } \\
Almond oil & $\ldots$ & $\ldots$ & $58 \cdot 5$ & $\ldots$ & $58 \cdot 6$ & & \\
Olive oil $\ldots$ & $\ldots$ & $\ldots$ & $52 \cdot 6$ & $\ldots$ & $52 \cdot 81$ & $\ldots$ & $52 \cdot 24$ \\
Earthnut oil & $\ldots$ & $\ldots$ & $62 \cdot 9$ & $\ldots$ & $63 \cdot 29$ & & \\
ation of IBr contained & $20 \cdot 7$ grammes per litre. & & C. A. M.
\end{tabular}

The Influence of Temperature on the Elaidin Reaction. A. P. Lidow. (Pharm. Zeit. f. Russland, xxxiv., 105-106, through Chem. Centralblatt).-By the action of nitrous oxides on oleic acid at $0^{\circ} \mathrm{C}$. a substance was produced which melted at $42^{\circ} \mathrm{C}$., while there was an increase in weight of 1 per cent. At $80-85^{\circ}$ there was an increase of weight of 16.6 per cent., and the iodine number of the product was only 9 per cent., whereas that of the oleic acid used was 88.6 per cent. It thus appears that at this temperature the free affinities of the unsaturated acids are satisfied. By long-continued action of the nitrous oxides the elaidic acid formed becomes fluid.

C. A. M.

Action of Alcoholic Soda Solution on Albumin and on Glue-yielding Substances. W. Fahrion. (Chem. Zeit., 1895, xix., 1000-1002.)-The author has already shown (Chem. Zeit., 1893, xvii., 434) that unsaturated fatty acids easily undergo polymerization, and that the polymerides are equally easily broken up by alcoholic soda solution; since albuminoids and gelatinoids have been regarded as polymerization products, it appeared to be of interest to study their behaviour with the same reagent.

Ten grammes of pure hide-powder were digested on the water-bath with 50 c.c. of alcoholic soda solution (8 per cent.), whereupon nearly all of it dissolved, a little ammonia being at the same time evolved. The alcohol was evaporated, the gelatinous residue dissolved in hot water, and the solution cooled and filtered. The filtrate was heated, acidified with hydrochloric acid-which expelled some carbonic acid and a little sulphuretted hydrogen-cooled, and filtered. The yellow filtrate was evaporated to dryness, the residue was dried at 110 to $120^{\circ}$ until constant in weight, and extracted with hot absolute alcohol; the alcoholic solution left a sticky red-brown syrup when evaporated.

This product is nearly ash-free and quite sulphur-free ; it cannot be crystallized. It has a sour odour and a disagreeable, bitter taste. It is insoluble in ether and in 
light petroleum, but dissolves easily in water and in alcohol. When heated for some time it swells up, but does not apparently decompose ; when cooled again it becomes brittle and easily powdered, but the powder is extremely hygroscopic. The substance is undoubtedly an acid, for it liberates carbonic acid from sodium carbonate in the cold, but its salts appear to be soluble, for its aqueous solution yields no precipitate.

An analysis of the acid, dried at $110^{\circ}$, indicated the formula $\mathrm{C}_{8} \mathrm{H}_{16} \mathrm{~N}_{2} \mathrm{O}_{6}$ for the compound, but the author is disposed to regard it as still containing a molecule of water, and as being in reality identical with the acid obtained by Schutzenberger by heating albumin with baryta under pressure, and called by him proteic acid, $\mathrm{C}_{8} \mathrm{H}_{14} \mathrm{~N}_{2} \mathrm{O}_{5}$. Towards the carbonates of the alkaline earths the acid behaves as though it were monobasic, but when it is heated with the alkaline earths themselves it behaves as a dibasic acid; this observation leads the author to conclude that proteic acid is a lactonic acid, which yields its appropriate salts when it reacts with carbonated alkalies, but salts of a dibasic acid containing one more molecule of $\mathrm{H}_{2} \mathrm{O}$ when heated with caustic alkalies.

The same acid was obtained by the similar treatment of glue, degreased ox-flesh, casein, human hair, horn, wool, and silk, indicating that the proteids in general are not aldehydic in constitution, as supposed by Loew, but lactonic.

More important from the point of view of this journal are the possible applications of this reaction of proteids in analysis.

To distinguish wool and silk from cotton, a sample of the fabric is warmed with 8 per cent. alcoholic soda solution; wool and silk dissolve with the exception of a little dark flocculent matter, but cotton is not attacked. Starch yields a black substance when treated with the alcoholic soda solution, but this is insoluble in alcohol, so that a quantitative estimation of albuminoids in presence of starch will probably be possible by this method.

Most oils and fats contain a small percentage of albuminous substance, and when they are saponified with alcoholic soda, this albumin is converted into proteic acid, which remains dissolved. When an excess of acid is added, and the liquid is shaken with petroleum ether for the purpose of separating the hydroxy-fatty acids (loc. cit.), which are insoluble in this solvent, the proteic acid also remains undissolved, and can be detected in the hydroxy-acids by means of its nitrogen. It is the presence of this proteic acid which has misled Jahoda and Simand in their investigation of dégras; these chemists have maintained that a peculiar nitrogenous constituent-the " dégrasformer "-is essential to genuine dégras, and can be recognised by its insolubility in petroleum ether. The author has shown, however, that by shaking the dégras with ether and water before saponification, the portion of the fatty acids which is insoluble in petroleum ether is free from nitrogen, consisting, in fact, of pure hydroxy-fatty acids. The method by which dégras is obtained necessitates the presence of a small quantity of hide-fibre, which will, of course, yield proteic acid when the dégras is saponified; thus the presence of nitrogen in that portion of the fatty acids of dégras which is insoluble in petroleum ether is not essential to genuine dégras, although it is indicative that the material has been obtained from chamois leather.

The author submits the following scheme for the analysis of chamois leather and of glacé kid : 
Two portions of 5 grammes of the finely-divided sample are weighed; the one is dried at $110^{\circ}$ to $120^{\circ}$ for the estimation of water, and subsequently ashed for the determination of mineral matter; the other is saponified in a porcelain dish with 8 per cent. alcoholic soda solution; the alkaline solution is washed into a separating funnel, acidified with hydrochloric acid, and when cold shaken with ether. The solid hydroxy-acids-the higher oxidation products of the jecoric acid which is characteristic of the fish oils-are thus left undissolved; they are dissolved in warm alcohol, and, after this has been evaporated, weighed. The ethereal solution contains the unsaponifiable matter, the fatty acids, and the liquid hydroxy-fatty acids. It is evaporated, and the weighed residue is treated with petroleum ether, which leaves the hydroxy-acids undissolved. The petroleum ether solution is shaken in a separatingfunnel with aqueous alcoholic soda solution; the fatty acids are thus extracted, the unsaponifiable matter (cholesterin) remaining dissolved in the petroleum ether. The alkaline solution of the fatty acids is evaporated to dryness, the residue dissolved in hot water, the solution decomposed with hydrochloric acid, and the fatty acids shaken out with petroleum ether (distilling completely at $75^{\circ}$ ).

The following table gives some analyses made according to this scheme. The small quantity of substance insoluble in the original alcoholic soda solution has been neglected, and the hide substance has been calculated by difference :

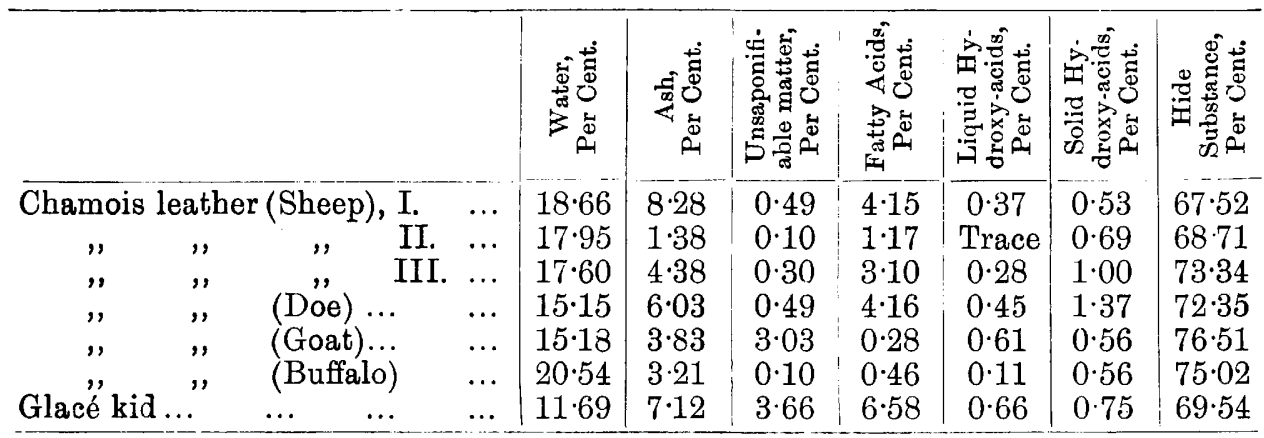

It is particularly noticeable from these figures how very little fatty matter serves to convert skins into chamois leather. The author is disappointed to find that the proportion of fatty acids present is, as a rule, much greater than that of the hydroxyacids, since, according to his theory, the curing of the hide-fibre depends on its combination with hydroxy-fatty acids; he has not yet, however, satisfied himself that the fatty acids are not merely derived from the natural fat of the skin.

A. G. B.

The Examination of Pepper. W. Busse. (Mitth. Gesundheitsamt., 505, through Zeit. angewand. Chem.)-In the author's opinion most of the analytical methods for the valuation of pepper, such as the determination of the moisture, ethereal oil, mineral matter, alkalies, and phosphoric acid, are inconclusive, since these constituents are common to the seed and the husk. The value of the cellulose and dextrose estimations must also be called in question. On the other hand, the brown colouring substances are only found in the husk, and their quantitative estimation 
will show the value of the pepper. To isolate them the following method is proposed. Five grammes of the sifted and dried pepper are treated with boiling absolute alcohol. The residue, after being freed from alcohol in the drying-oven, is ground up with a little water in a basin, and then washed into a flask with 50 to 60 c.c. of boiling water. Twenty-five c.c. of a 10 per cent. solution of soda are added, and the flask is warmed on the water-bath for five hours with constant shaking. Concentrated acetic acid is next added, until the liquid is only feebly alkaline, then 250 c.c. of water, and the flask is well shaken. After twelve hours the liquid is filtered with the aid of a suction-pump.

To 50 c.c. of the filtrate concentrated acetic acid is added to acid reaction, followed by 20 c.c. of a 10 per cent. solution of lead acetate in dilute acetic acid. After mixing, the liquid is diluted to a 100 c.c. with water, well shaken and filtered. Ten c.c. of the filtrate are decomposed with 5 c.c. of $\mathrm{H}_{2} \mathrm{SO}_{4}(1: 3)$ and 30 c.c. of alcohol, the precipitate filtered after some time, washed with alcohol, and the lead sulphate ignited and weighed in the usual manner, and the amount of lead calculated.

The amount of lead (in grammes) which has been obtained by the process from 1 gramme of dried pepper, may be described as the "lead number." The figures given by the different kinds of pepper are :

\begin{tabular}{lllllll} 
& & \multicolumn{4}{c}{ Lead Number. } \\
White pepper & $\ldots$ & $\ldots$ & $\ldots$ & 0.006 & to & 0.027 \\
Black pepper & $\ldots$ & $\ldots$ & $\ldots$ & 0.054 &, & 0.075 \\
Husks $\ldots$ & $\ldots$ & $\ldots$ & $\ldots$ & 0.129 & " & 0.157 \\
Pepper dust & $\ldots$ & $\ldots$ & $\ldots$ & 0.109 & , & 0.122
\end{tabular}

The author concludes that this method, taken in conjunction with the determination of the ash and sand and the microscopical examination, should be of great assistance in estimating the value of pepper.

C. A. M.

Simple Method of Detecting " Poivrette" in Ground Pepper. D. Martelli. (Staz. Sper. Ag. Ital., xxviii., 53.)-Several methods other than microscopical ones have been proposed for the detection of "poivrette" (ground olive-stones). Thus, Gillet (Bull. Soc. Chim., 50, 173) used tincture of iodine (6.5 gr. I in 120 c.c. 90 per cent. alcohol), which coloured pepper brown or dark chestuut, while olive-stones became bright yellow. Chevreau (Rep. Pharm., 1889, p. 203) does not consider this reliable, and employs a mixture of 1 part aniline with 3 parts acetic acid, which colours "poivrette" a light yellow. Jumeau (Journ. Pharm. Chim., 1889, p. 442) used a mixture of 5 grammes iodine in 100 c.c. of a mixture of alcohol and ether, the colours produced being the same as with Gillet's test. Pabst (La Pratique des Essais Commerciaux-Matières Organique, Halphen, p. 21) tests by adding a little of a solution of dimethyl-paraphenylene-diamine; after a short time the ligneous particles foreign to pepper become carmine-red, while pepper at most is superficially tinged pink.

The author proposes the following test: Digest for two or three days 1 gramme of phloroglucol in 50 or 60 c.c. of hydrochloric acid sp. gr. 1.1, and decant the clear solution. To about $\frac{1}{2}$ gramme of the sample of pepper add enough of the reagent 
to cover it, and heat cautiously till fumes of hydrochloric acid begin to come off. "Poivrette" and like substances (e.g., ground-up shells of almonds, walnuts, nuts, etc.) give a very intense cherry-red colour, which is sharply distinguished by the naked eye from the yellow or faintly red-brown colour of the pepper. On adding to the mass a little water, and decanting the liquid, a violet-red powder is left, which consists almost entirely of "poivrette," etc., stained by the reagent.

H. D. R.

A Comparative Examination of the Constitution of Different Meat Extracts. A. Stutzer (Zeit. angew. Chem., 1895, p. 157).-The meat extracts most frequently met with are those of the Liebig and Kemmerich Companies and the various Bovril preparations. According to the author's analysis, these contain :

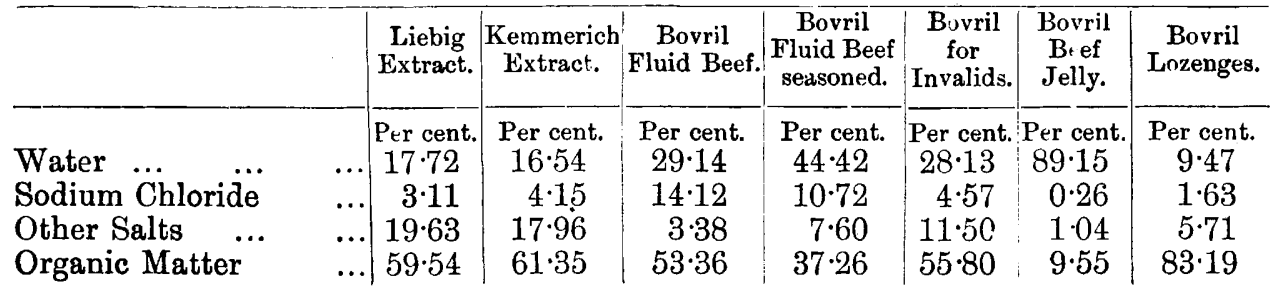

The most important constituents of the organic matter are those containing nitrogen. Nitrogen was present in the form of-

\begin{tabular}{|c|c|c|c|c|c|c|c|}
\hline \multirow[t]{2}{*}{$\begin{array}{l}\text { (a) Albumose Peptone } \\
\text { (b) Pancreas Peptone... }\end{array}$} & $\begin{array}{l}0.56 \\
2.72\end{array}$ & $\begin{array}{l}1 \cdot 24 \\
2 \cdot 38\end{array}$ & $\begin{array}{l}1 \cdot 23 \\
3 \cdot 36\end{array}$ & $\begin{array}{l}0.34 \\
1.39\end{array}$ & $\begin{array}{l}1 \cdot 26 \\
3 \cdot 36\end{array}$ & $\begin{array}{l}0 \cdot 16 \\
0 \cdot 48\end{array}$ & $\begin{array}{l}2 \cdot 06 \\
6 \cdot 06\end{array}$ \\
\hline & $3 \cdot 28$ & $3 \cdot 62$ & 4.59 & $1 \cdot 73$ & $4 \cdot 62$ & 0.64 & $8 \cdot 12$ \\
\hline \multirow{3}{*}{$\begin{array}{l}\text { (c) Flesh bases and de- } \\
\text { composition products } \\
\text { soluble in alcohol } \\
\text { (d) Ditto, insoluble in } \\
\text { alcohol } \\
\text {... }\end{array}$} & $4 \cdot 05$ & $3 \cdot 69$ & $1 \cdot 06$ & $1 \cdot 16$ & $1 \cdot 78$ & $0 \cdot 21$ & 0.55 \\
\hline & $1 \cdot 34$ & $1 \cdot 25$ & $1 \cdot 16$ & 0.89 & 0.82 & $0 \cdot 20$ & $1 \cdot 16$ \\
\hline & $5 \cdot 39$ & $4 \cdot 94$ & $2 \cdot 22$ & 2.05 & $2 \cdot 60$ & 0.41 & $1 \cdot 71$ \\
\hline \multirow{3}{*}{$\begin{array}{l}\text { (e) Albumin } \\
\text { (f) Muscular Fibre }\end{array}$} & $0 \cdot 12$ & 0.09 & 0.31 & 0.08 & $0 \cdot 24$ & - & 0.42 \\
\hline & - & - & $0 \cdot 73$ & 0.90 & $0 \cdot 70$ & -- & 0.57 \\
\hline & 0.12 & 0.09 & $1 \cdot 04$ & 0.98 & 0.94 & - & 0.99 \\
\hline \multirow{3}{*}{$\begin{array}{l}\text { (g) Gelatin } \ldots \\
\text { (h) Ammonium Salts }\end{array}$} & 0.04 & 0.05 & 0.09 & $0.09^{\circ}$ & 0.15 & $0 \cdot 29$ & $0 \cdot 70$ \\
\hline & 0.48 & 0.46 & 0.31 & $0 \cdot 27$ & 0.38 & $0 \cdot 12$ & 0.42 \\
\hline & 0.52 & 0.51 & 0.40 & 0.36 & 0.53 & 0.41 & $1 \cdot 12$ \\
\hline Total Nitrogen... & $9 \cdot 31$ & $9 \cdot 16$ & 8.25 & $5 \cdot 12$ & $8 \cdot 69$ & $1 \cdot 46$ & 11.94 \\
\hline
\end{tabular}

With regard to this table, the author remarks :

I. The value of a meat extract as a food material depends on the amount of peptone present; and of the two kinds referred to under $(a)$ and $(b)$, the albumose 
peptone probably possesses greater nourishing power than the other. Calculating for 1 part of nitrogen $6 \frac{1}{4}$ parts of peptone, the amount of the latter present in the various preparations is as follows:

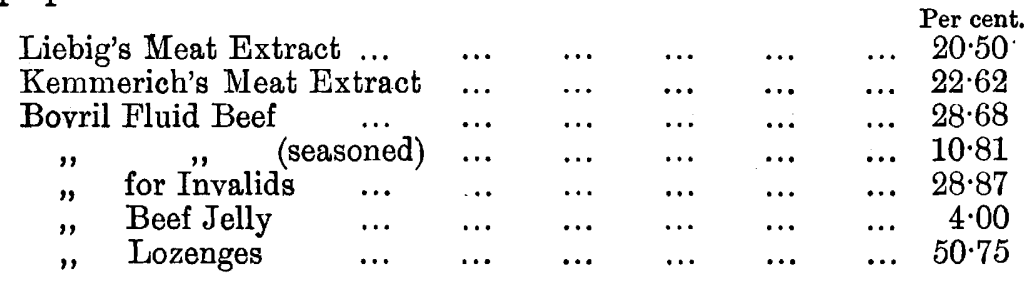

Thus the statement that 1 part of bovril fluid beef seasoned contains a greater amount of nourishing material than 50 parts of any other meat extract is quite inadmissible.

II. The value of a meat extract as a stimulant (apart from the action of the salt) depends especially on the quantity of the substances classed under $(c)$ and $(d)$. In this respect the Liebig and Kemmerich preparations take the first place.

III. In addition to albumin, the bovril preparations contain considerable quantities of muscular fibre (up to 6 per cent.).

IV. Gelatin should be regarded as a worthless constituent, and should be removed from meat extracts as completely as possible.

$$
\text { C. A. M. }
$$

Determination of Glycerol in Wines, and Indirect Estimation of Mannitol. G. Mancuso-Lima and G. Sgarlata. (Staz. Sper. Ag. Ital., xxviii., 236.)-The authors find that the process of Oliveri and Spica (Gazzetta, xx., 734), who distil the glycerol under reduced pressure at $200^{\circ}$, and titrate with $\frac{\mathrm{N}}{10}$ permanganate, too long and tedious when many samples are to be examined.

They base their process on the fact that ammoniacal lead hydroxide, recently prepared, completely precipitates both glucose and mannitol, and that the glycerol can be titrated by permanganate in the filtrate after removing the lead and adding sulphuric acid.

1 c.c. of normal permanganate is equal to 01 gramme glycerol, 0081 gramme glucose, and 0089 gramme mannitol.

The direct estimation of glycerol is performed by concentrating 25 c.c. of the wine to a syrup on the water-bath, and precipitating in the cold by ammoniacal hydroxide of lead (obtained by adding a slight excess of basic acetate of lead, and then an excess of ammonia); the liquid is filtered rapidly through a filter, contained in a funnel, over the top of which is placed another funnel connected with a tube containing caustic potash, and the filtrate and washings collected in a beaker, acidified with concentrated sulphuric acid, and the sulphate of lead separated by filtration; the solution is brought to the boil, and titrated hot with normal permanganate.

By precipitating with basic acetate of lead, and proceeding as before, the glucose and mannitol (if present) are left in solution, and are titrated with the glycerol with permanganate; by estimating the glucose by Fehling's solution, and subtracting the amount of permanganate equal to this and to the glycerol, from the total used, the remainder is equivalent to the mannitol.

H. D. R. 
The Detection of Salicylic Acid in Wine. M. Spica. (Staz. Sper. Ag. Ital., xxviii., 246.)-The reaction between ferric chloride and salicylic acid, after shaking out with ether, will not detect less than .003 gramme per litre; ether, chloroform; and carbon bisulphide all extract tartaric acid, tannin, and acetic acid from the wine, which interfere with the salicylic-reaction, and render the test less delicate. By evaporation of the ether-extract, and extraction of the residue with petroleum ether, the test is more delicate, .002 gramme being detected.

The author heats the ether extract with nitric acid, by which means the salicylic acid is transformed into trinitrophenol (picric acid). He proves that genuine wines give no extract to ether from which picric acid is formed, and that saccharine (Fahlberg) does not yield picric acid. The delicacy of the reaction is such that 0002 gramme salicylic acid per litre can be detected.

The test is performed thus: 10 c.c. of wine are acidified with a few drops of hydrochloric acid, and shaken with an equal volume of ether; half the ether is removed and filtered (this is not absolutely necessary); the ether is evaporated, and one drop of nitric acid is added, and the mixture cautiously heated over a flame; a few drops of ammonia are added, and then 1 c.c. of water and a piece of wool, previously treated with potash solution, and then with ether to remove fat; the solution is warmed, and the wool, after washing and drying between blotting-paper, is examined; it is dyed yellow, if salicylic acid is present. By comparison with a set of standard wools, prepared from wines to which known quantities of salicylic acid have been added, an estimation may be made.

H. D. R.

Estimation of Potassium Sulphate in Wine. L. Hugouneng. (Journ. Pharm. Chim., 1895 [6], i., 349 ; through Chem. Zeit.)-The author notes that the percentage of sulphuric acid (weighed as barium sulphate) found in a wine depends on whether the estimation has been made in the wine itself or in the aqueous extract of the ignited total solids. The ash yields a higher percentage than does the wine itself. This discrepancy is probably due to the existence of sulphur compounds other than potassium sulphate in the wine, which become potassium sulphate when the residue is ignited. It will be found that this difference between the sulphuric acid in the wine and in the ash of the wine is characteristically high (0.2 gramme per litre) in wine from dried fruits, a fact which proves useful in the diagnosis of a particular sample.

A. G. B.

The Determination of Tannin in Wine. A. Vigna. (Staz. Sper. Ag. Ital., xxviii., 19.)-Two modifications of the Carpené-Lowenthal method (precipitation with ammoniacal zinc acetate, heating to drive off excess of ammonia, and titration of the precipitate after dissolving in sulphuric acid by permanganate) are proposed. In the first, 25 c.c. of an 8 per cent. solution of zinc acetate are added to 50 c.c. of wine, and neutralized exactly with dilute ammonia, and the precipitate collected on a plain filter and washed four times with cold water. The filter is then placed on a glass plate, and the precipitate washed off by a stream of water from a wash-bottle; 20 c.c. dilute sulphuric acid ( 1 part acid to 4 parts water) and 20 c.c. of indigo 
solution are added, and the titration is performed in the usual manner with permanganate. In the second modification, 40 c.c. of an 8 per cent. solution of potash alum are used in place of the zinc acetate, the remainder of the process being the same as before.

The author shows that both modifications give the same results as the CarpenéLowenthal method with wines, and theoretical results with pure tannins. He prefers the alum method, as being the more expeditious.

H. D. R.

Detection of Fluorinelin Wine. G. Nivière and A. Hubert. (Monit. Scient., 1895 [4], ix., 324 ; through Chem. Zeit.) - 100 c.c. of the wine are made feebly alkaline with ammonium carbonate, the solution is boiled, and 2 to 3 c.c. of a 10 per cent. solution of calcium chloride are added. After boiling for a few minutes, the liquid is filtered, the filter ashed, the ashes mixed with a third of their weight of precipitated silica, and the mixture transferred to a test-tube, together with a mixture of equal parts of fuming sulphuric acid and concentrated sulphuric acid $\left(66^{\circ} \mathrm{Bè}\right)$. The testtube is fitted with a cork, which carries a $U$-tube 4 millimetres in diameter, and having three bulbs ( 7 to 10 millimetres diameter) blown in it. In the centre bulb one drop of water is placed. The test-tube is now heated, whereupon any fluorine will be evolved as silicon tetrafluoride, which will be decomposed by the drop of water, yielding the usual gelatinous silica and solution of hydrofluosilicic acid. In the event of mere traces of fluorine being present, no visible separation of silica in the water-drop will be noticed; in this case the $U$-tube must be washed out with alcohol and the washings evaporated to dryness, when the silica will be detected. A blank test must be made with the filter-paper, and great stress must be laid upon the fine state of division of the silica and upon the prescribed strength of the sulphuric acid.

For quantitative estimations the $\mathrm{U}$-tube is washed with water, the washings are filtered, and to the filtrate is added a solution of potassium acetate in dilute alcohol ; the precipitated potassium silicofluoride is filtered, washed with dilute alcohol $(1: 1)$, dried, and weighed. The factor 0.5177 will convert the weight into the corresponding weight of fluorine. One litre of wine will be necessary for a quantitative determination. The author has detected the fluorine corresponding with 1 gramme of ammonium fluoride in one hectolitre of wine with rapidity and certainty by this method.

A. G. B.

Detection of Fluorine in Beer. R. Hefelmann and P. Mann. (Pharm. Centr.-H., 1895, xvi., 249 ; through Chem. Zeit.)-A fluoride which has been added to finished beer as a preservative may be detected as follows: To 500 c.c. of the beer, freed from carbonic acid-either by exposure in a thin layer, or by heating at $40^{\circ}$ 1 c.c. of a mixture of equal volumes of calcium chloride solution (10 per cent.) and barium chloride solution ( 10 per cent.) is added; this is followed by 0.5 c.c. of acetic acid (20 per cent.) and 50 c.c. of alcohol (90 per cent.). The liquid is allowed to remain for twenty-four hours in the cold, in order that the precipitated calcium fluoride and barium silico-fluoride may settle; it is then filtered through a small filter, the last traces of the precipitate being either washed out of the beaker by 
means of the filtrate, or wiped out by means of filter-paper. The precipitate and filter are dried without being washed, and transferred to a platinum crucible (20 c.c.); 1 c.c. of strong sulphuric acid is added, the crucible is covered with a clock-glass (which has been waxed and then marked with a style), this is filled with water, and the crucible is heated at $100^{\circ}$ for two hours. By this method so little as 0.7 milligrammes of fluorine in 100 c.c. of beer can be detected with certainty.

A. G. B.

The Detection of Bloodstains in Forensic Cases. F. Gantter. (Zeit. für anal. Chem., 1895, Zweites Heft, pp. 159-160.) - The detection of bloodstains on rusty iron is a matter of extreme difficulty, owing to the fact that in most cases it is impossible to obtain hæmine crystals from the blood which has been made insoluble by the iron oxide. Very frequently, too, it is of the greatest importance to prove the complete absence of blood.

The behaviour of the blood towards hydrogen peroxide is a valuable means for the latter purpose. The slightest trace of blood-substance brought into contact with a drop of this reagent causes an immediate evolution of oxygen, so that the drop in a very short time becomes changed into a white froth.

The best method of observing the reaction is as follows: A drop of the solution of the suspected blood-material, or where a solution is not possible (as in the case of spots on rusty iron), a small piece of the rust scraped off, is placed on an object-glass with a piece of black paper underneath. After moistening with a drop of water made very feebly alkaline a drop of hydrogen peroxide is added, and when the slightest trace of blood-substance is present numerous comparatively large bubbles of gas are developed, which after a short time unite, forming a fine snow-white scum, which remains for some hours. It is characteristic that the scum forms from the outside of the drop inwards, so that it is surrounded by a ring of clear fluid. In the case of rust containing blood, the development of gas does not proceed from all the particles of rust but only from those to which blood is attached.

It is impossible to mistake this appearance for that formed by air-bubbles. On moistening the rust with the alkaline water numerous air-bubbles are frequently formed, but these are quickly dissipated by touching them with a thin glass rod before adding the hydrogen peroxide:

If the reaction does not occur, it is certain that the rust contains no blood; but, unfortunately, its occurrence cannot be regarded as proof positive of the presence of blood, since other animal fluids (e.g., pus) behave in a similar way towards hydrogen peroxide.

Apart from its value as a negative proof, the reaction is also of use in testing whether crystals supposed to be hæmine crystals really are so. The age of the spots on the rust appears to make no difference. Stains six months old responded to the test as sharply as when fresh.

C. A. M.

Examination of Medicaments containing Iodine. G. Deniges. (Journ. Pharm. Chim., 1895 [6], i., 354; through Chem. Zeit.)-Since a large number of organic iodine preparations easily yield their iodine as alkali-metal iodide, it is possible 
to assay them by the usual methods for titrating iodine. Iodoform, is decomposed in a test-tube by heating it for a short time with 1 c.c. of nitric acid and 2 c.c. of hydrochloric acid; 10 c.c. of water are added and 2.5 c.c. of sodium bisulphite solution $\left(36 \cdot 4^{\circ} \mathrm{B}\right)$. The iodine having been thus completely converted into hydriodic acid, 10 c.c. of ammonia are added, and the whole is made up to 100 c.c. Fifty c.c. are then mixed with 15 c.c. of ammonia and 25 c.c. of $\frac{\mathrm{N}}{10}$ silver nitrate solution, made up to 100 c.c. and filtered. Fifty c.c. of the filtrate are mixed with 50 c.c. of water and 10 c.c. of $\frac{\mathrm{N}}{10}$ potassium cyanide solution; a few drops of potassium iodide solution (20 per cent.) are next added, and the liquid titrated with $\frac{\mathrm{N}}{10}$ silver nitrate solution until a permanent turbidity is produced.

Di-iodoform is decomposed by heating it in a long test-tube with 1 c.c. of pure sulphuric acid until no more iodine vapour is evolved. The iodine will condense on the sides of the tube, and, after the addition of a few drops of nitric acid, is converted into hydriodic acid by sodium bisulphite. Aristol is decomposed by heating 0.125 gramme with 2.5 c.c of alcoholic potash (10 per cent.) and 0.5 gramme of powdered potassium nitrate, until the mass is dry and ignited. The residue is dissolved in water, reduced with sodium bisulphite and titrated as described above.

A. G. B.

On the Estimation of Sulphur in Petroleum. Fr. Heusler. (Zeit. für angewand. Chemie, 1895. Heft 10, pp. 285-286.)-Several of the methods for estimating sulphur in mineral oils (e.g., those of Kast and Lagai. Dingl., 284, 69, and Heusler, Ber., 28, 493) cannot be relied upon when the amount to be determined is very small-0.02 gramme and less.

In his handbook of "Chemical Technology," Fischer describes a process for estimating sulphur in coal-gas, which consists in conducting the products of combustion through a tube bent many times, in which the sulphur is oxidized by a solution of hydrogen peroxide.

The principle of this method has been adapted by the author to the estimation of small quantities of sulphur in mineral oils. His apparatus consists of a small petroleum lamp, to be placed under a cylinder with an opening in the side near the bottom for air to enter, and an opening at the top for the gases to pass off. By means of a special contrivance, which cannot be clearly described without the illustration, the sulphur in the products of combustion is oxidized by a solution of potassium permanganate, which drops from a spiral worm, meets the gas, and then falls into a small flask.*

In making the estimation, 20 to 30 grammes of the oil are placed in the lamp, which is then weighed, lit, and placed under the cylinder. By means of an aspirator at the top a current of air is drawn through the apparatus, and is so regulated that the combustion is complete. The lamp may then be left burning for twelve hours or

* The complete apparatus may be obtained from C. Gerhardt, Marquart's Lager Chemischer Utensilien, Bonn. 
longer. At the end of the experiment it is again weighed, and the weight deducted from the previous weight gives the amount of oil consumed. The permanganate solution is boiled with $\mathrm{HCl}$ and filtered, and the sulphuric acid precipitated with $\mathrm{BaCl}_{2}$. C. A. M.

Estimation of Thiophen in Benzene. G. Deniges. (Compt. rend., 1895, cxx., 781; through Chem. Zeit.)-This can be effected by precipitating the thiophen in the form of the compound $2\left(\mathrm{HgO}, \mathrm{HgSO}_{4}\right), \mathrm{C}_{4} \mathrm{H}_{4} \mathrm{~S}$, as follows: Two c.c. of the benzene are added to 20 c.c. of a solution of basic mercuric sulphate ( 50 grammes $\mathrm{HgO}, 200$ c.c. $\mathrm{H}_{2} \mathrm{SO}_{4}, 1,000$ c.c. water) contained in a well-stoppered flask (60 c.c.). The stopper is wired down, and the flask heated in a water-bath for about a quarter of an hour. When cold the liquid is filtered through a weighed filter, which is then washed with hot water, dried at $110-115^{\circ}$, and weighed. The increase in the weight of the filter is multiplied by the factor 0.0758 to obtain the weight of thiophen in the sample.

If objection be taken to the heating of the flask, this may be avoided by dissolving the benzene in some solvent miscible with water. A freshly-prepared mixture of 10 c.c. of the mercuric sulphate solution with 30 c.c. of acetone-free methyl-alcohol will dissolve 4 c.c. of pure benzene to a clear solution; but if thiophen be present a precipitate will form in a short time, and may be weighed in the manner described above. Care must be taken that the basic mercuric sulphate is in excess, otherwise the compound $2 \mathrm{HgO}, \mathrm{HSO}_{4}, \mathrm{C}_{4} \mathrm{H}_{4} \mathrm{~S}$ is likely to be formed.

A. G. B.

Luteol; A New Indicator. W. Autenrieth (Arch. Pharm., 1895, cexxxiii., 43; through Chem. Zeit.) - Luteol or chlorohydroxydiphenyl-quinoxaline is obtained from phenacetin. It crystallizes in slender yellowish needles, melts at $246^{\circ}$, is insoluble in water and sparingly soluble in alcohol, and can be sublimed It serves as an indicator in those cases where litmus or phenolphthalein is inapplicable. In acid liquids it is perfectly colourless, but intensely yellow in alkaline solutions.

A. G. B.

The Composition of some "Vegetable" Colouring Matters for use in Confectionery, etc. G. Posetto. (Zeits. Nahrungsm. Unters. u. Hygiene, 1895, ix., 150 ; through Chem. Zeit. Rep., 1895, 188.)-A set of these "vegetable" colours, consisting of pastes mostly insoluble in water and alcohol, have been examined and were found to be tin lakes. When dry they contain from 72 to 80 per cent. of tin oxide, and as in their moist condition they contain about 70 per cent. of water, the amount of tin present must be at least 20 per cent. The blue paste is pure indigo-carmine, with 2.5 per cent. of ash, chiefly sulphates.

F. H. L.

A Characteristic Reaction of Citric Acid. I. Stahr. (Nordisk pharm. Tidskrift, 1895, ii., 141; through Chem. Zeit. Rep., 1895, 187.)-If 10 mgrms. of eitric acid be dissolved in 1 c.c. of water, a few drops of $\frac{x}{10}$ permanganate added and the 
liquid warmed till the colour has vanished, and 3 to 5 drops of saturated bromine water dropped in, on cooling, a white crystalline precipitate appears, which, on the addition of caustic soda, yields the odour of bromoform. The reaction will detect $0.2 \mathrm{mg}$. of citric acid.

F. H. L.

The Estimation of 'Available' Phosphoric Acid in Thomas Slag. G. Sani. (Staz. Sper. Ag. Ital., xxviii., 275.)-The author takes 5 grammes of the slag, adds 100 c.c. of water, and saturates at a boiling temperature with 10 per cent. citric acid solution, adds 200 c.c. of ammonium citrate solution; the mixture is then heated for an hour on the water-bath, with carefal shaking, and made up to 500 c.c. The phosphoric acid dissolved is then estimated in the usual manner. H. D. R.

The Methods of Analysis of Copper Salts. L. Sostegni. (Staz. Sper. Ag. Ital., xxviii., 167.) - The author shows that in the electrolytic method of determination of copper, arsenic, if present, is deposited at the same time. This method is too long, and requires too much attention.

Precipitation with zinc gave slightly high results, due to the deposition of a basic copper salt, and possibly, also, of cuprous chloride.

Titration with sodium sulphide, using as indicator paper prepared with alkaline lead acetate, was found to be inaccurate. The method of titration with ferrocyanide, using paper moistened with ferric chloride solution as indicator, was not found to be delicate enough for commercial purposes.

One gramme of the copper sulphate to be tested is dissolved in 25 c.c. of water and 15 c.c. of Soxhlet's alkaline tartrate solution added, and into this solution 20 c.c. of a 1 per cent. solution of glucose are dropped, little by little, the whole being boiled, and the boiling continued for five minutes. 25 c.c. of boiling water are now added, and after allowing the cuprous oxide to settle for a short time, the solution is decanted through a filter; boiling water is at once poured on the cuprous oxide, and the filter is then well washed before the precipitate is transferred to it. The cuprous oxide is then transferred to the filter, washed till the water which runs through is neutral, and the filter and its contents dried in a stove. The bulk of the precipitate is transferred to a platinum boat, the filter burnt and placed at one end of the boat, the whole then transferred to a tube, a piece of asbestos-paper being placed under the boat, and the $\mathrm{Cu}_{2} \mathrm{O}$ reduced in a current of hydrogen. The results are very good, and iron does not interfere if present in traces. If notable quantities are present, the iron should be brought to the ferric state and precipitated by ammonia.

The cuprous oxide may be also converted into cuprous sulphide, and weighed as such, by placing a little sulphur in the boat (which should then be of porcelain) before placing it in the tube, and proceeding as before.

H. D: R.

Estimation of Tellurium in Coppэr Bullion. C. Whitehead. (Jour. Amer. Chem. Soc., xvii., 1895, 280-281.)-From 25 to 50 grammes of the bullion are 
dissolved in $\mathrm{HNO}_{3}$ of $32^{\circ} \mathrm{Bé}$, and the excess of acid removed by boiling. To this solution ferric nitrate solution, corresponding to 0.25 gramme of iron, is added. Then an excess of ammonia, and the precipitate is washed with dilute ammonia until all the copper salts are completely removed. If necessary, the precipitate is dissolved and re-precipitated. The residue on the filter, consisting of iron tellurite and selenite, is dissolved in $\mathrm{HCl}$, an excess of tartaric acid added, the solution made alkaline with $\mathrm{KOH}$, and $\mathrm{H}_{2} \mathrm{~S}$ passed through, when the selenium and tellurium dissolve as sulphides. The liquid is filtered, dilute $\mathrm{HCl}$ added to decompose the alkaline sulphides, and after standing in a warm place to remove $\mathrm{H}_{2} \mathrm{~S}$, again filtered. The tellurium and selenium sulphides are dissolved in aqua regia, the solution evaporated to dryness, then taken up with $\mathrm{HCl}$, and the tellurium and selenium precipitated by a current of $\mathrm{SO}_{2}$ passed in to saturation. After standing twelve hours in a warm place, the precipitate is filtered on a weighed filter, dried at $100^{\circ}$, and the tellurium and selenium weighed together. The selenium is separated by boiling the precipitate in concentrated $\mathrm{KCN}$ solution, filtering, and adding $\mathrm{HCl}$, when the selenium is deposited as a brick-red precipitate, which is dried at $100^{\circ}$ and weighed.

The tellurium is estimated by difference, or the small amount dissolved by the $\mathrm{KCN}$ solution may be precipitated by $\mathrm{SO}_{2}$, after removal of the selenium, added to the original residue, and the whole dried at $100^{\circ}$ and weighed.

C. A. M.

The Estimation of Antimony as Antimonious Antimoniate. Otto Brunck. (Zeit. für anal. Chem., 1895, Zweites Heft, pp. 171-174.)-This method of estimating antimony has for some time past been in disrepute, since Bunsen showed that the tetroxide was volatile on ignition, and lost as much as 0.1 gramme in six hours. This observation being opposed to the general statements that $\mathrm{Sb}_{2} \mathrm{O}_{4}$ is infusible and nonvolatile led the author to investigate the method.

Antimony, obtained pure by reducing potassium antimoniate with potassium cyanide, was weighed into a porcelain crucible and oxidized with $\mathrm{HNO}_{3}$, the crucible being covered with a watch-glass. The contents were then ignited in the crucible without a lid until constant in weight, and the amount of antimony calculated from the $\mathrm{Sb}_{2} \mathrm{O}_{4}$ found. In six determinations the amount found corresponded to within a milligramme of that taken. The uncovered crucible could be kept at a red heat for several hours without losing the slightest amount in weight.

Experiments were then made to discover under what conditions a loss by volatilization could occur, and it was found that the decomposition of the $\mathrm{Sb}_{2} \mathrm{O}_{4}$ into the trioxide and oxygen admitted of a simple explanation. Where the crucible was covered with a lid the flame gases were caught by its projecting edge, conducted into the crucible, and exercised a reducing action there. When the interior of the crucible had free contact with the atmospheric air, this reducing action was altogether obviated.

With the precaution of igniting the residue in an uncovered crucible the method is not only very rapid and exact, but where small quantities of antimony are to be estimated is to be preferred to any other.

C, A. M. 
The Superiority of Barium Hydroxide Solution as an Absorbent in Carbon Determinations in Steel. J. O. Handy. (Journ. Amer. Chem. Soc., 1895, xvii., pp. 247-251.) - The absorption of $\mathrm{CO}_{2}$ by means of $\mathrm{KOH}$ in Geissler bulbs has the disadvantage that variations of the temperature and degree of moisture in the air of the laboratory produce errors which the greatest care can only partially eliminate By using barium hydroxide instead of potash these errors are avoided, and it is possible to finish the analysis in at least three ways. 1. The barium carbonate may be filtered off, washed, ignited, and weighed. 2. The excess of barium hydroxide may be titrated $(a)$ with standard oxalic acid without filtering; $(b)$ with standard $\mathrm{H}_{2} \mathrm{SO}_{4}$ after filtering off the barium carbonate. Phenolphthalein is used as the indicator in each case, but the end reaction with $\mathrm{H}_{2} \mathrm{SO}_{4}$ is sharper.

In the estimation, 10 grammes or more of a steel containing 0.06 per cent. carbon, or 5 grammes of one containing 0.20 per cent., are dissolved by shaking in a stoppered bottle with a mixture of copper and potassium chloride solution $(1 \mathrm{lb}$. in 1,400 c.c. of water) and $\mathrm{HCl}$. 600 c.c. of the former and 40 c.c. of the acid are used for 10 grammes of steel, and proportionately more or less for other amounts. The liquid is filtered through asbestos which has been ignited in oxygen, and the carbon residue dried at $100^{\circ}$, and burned in the usual way in the combustion tube. The products of combustion pass through a $U$-tube with $\mathrm{CaCl}_{2}$ in the first limb and anhydrous copper sulphate in the other, and then through two absorption tubes, each containing 50 c.c. of barium hydroxide solution. When the combustion is complete, and pure air or oxygen has been passed through to expel all carbon dioxide, the absorption tubes are disconnected and their contents filtered. During filtration air free from $\mathrm{CO}_{2}$ is kept playing on the surface of the barium hydroxide solution, to prevent further formation of carbonate. The precipitate is washed with distilled water free from $\mathrm{CO}_{2}$, and the excess of barium hydroxide titrated with decinormal $\mathrm{H}_{2} \mathrm{SO}_{4}$, of which 1 c.c. $=0.0006$ gramme carbon. The barium hydroxide solution used contains about 20 grammes per litre.

The following results were obtained in experiments to test the method.

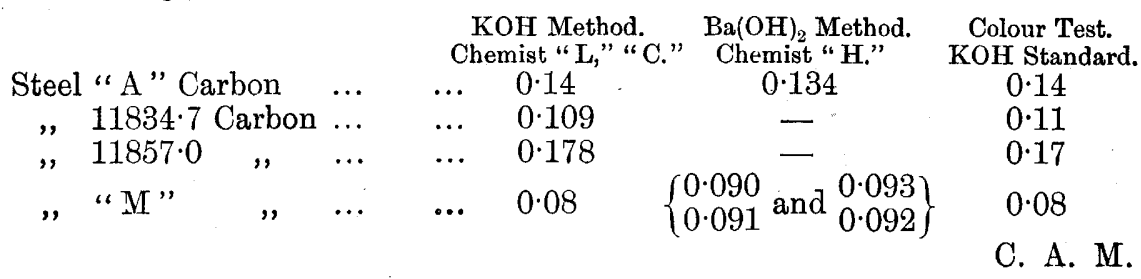

Lead Carbonate as an Agent for opening up Silicates. P. Jannasch. (Zeits. Anorg. Chem., 1895, viii., 364 ; through Chem. Zeit.)-The silicate is fused with pure lead carbonate in a platinum crucible. The melt is loosened by plunging the hot crucible in cold water, and is dissolved in strong nitric acid. The silica is separated by evaporation to dryness, and the lead separated from the filtrate; on the addition of $\mathrm{HCl}$, most of the lead separates as chloride, and the remainder is removed as sulphide. The lead carbonate is best prepared by precipitating lead acetate with amınonium carbonate, and washing with hot water.

A. G. B. 